\title{
Role of Mercerizing Condition on Physical and Dyeing Properties of Cotton Knit Fabric Dyed with Reactive Dyes
}

\author{
Shuvo Brahma*, Md. Rashedul Islam and Rasheda Begum Dina \\ Department of Wet Process Engineering, Bangladesh University of Textiles, Tejgaon, I/A, Dhaka-1208, Bangladesh
}

Received 10 June 2018, Accepted 12 Aug 2018, Available online 16 Aug 2018, Vol.8, No.4 (July/Aug 2018)

\begin{abstract}
This work aims on the assessment of mercerizing efficiency as well as the effect of mercerizing condition on physical properties of cotton knit fabric and subsequently the dyeing properties of mercerized textiles. Cotton knit fabrics were mercerized by varying the concentration of caustic soda and the mercerized fabrics were dyed with 3\% Reactive dyes by varying dyeing temperature. Mercerizing efficiency was assessed by BAN and physical properties were assessed in terms of moisture regain, tensile strength and brightness of cotton goods. It was found that all the parameters increased with the increase of concentration of $\mathrm{NaOH}$. In terms of color strength and colorfastness properties, it was observed that, with the increment of dyeing time the shade became more prominent with better fastness rating.
\end{abstract}

Keywords: Concentration, caustic soda, physical properties, reactive dyes, temperature, color fastness.

\section{Introduction}

Mercerization is a physico-chemical process where cotton goods are treated with 15 - 25\% (21 - 22\%

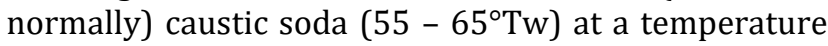
$20-30^{\circ} \mathrm{C}$. It is not a fibre purification process, but it does induce desirable changes in cotton yarn and fabric properties. The process takes its name from John Mercer, who in 1850 observed that there was a general swelling and shrinking effect on cotton fabric when treated with caustic soda solution. Horace Lowe (1889-90) later demonstrated the high luster of mercerized cotton by maintaining tension during treatment. The objective of mercerizing is to swell the cotton fibre, increasing its luster, tensile strength (as well as retain it after an easy-care finish), dimensional stability and dye ability (in terms of uniformity and color yield) (Choudhury, 2017).

Benefits due to Mercerization

- Increased tenacity

- Increased luster

- Increased reactivity

- Increased resistance

- Enhanced dye ability

- Enhanced color fastness

Commercial applications of mercerization are carried out to enhance the value of the finished fabric for the

*Corresponding author's ORCID ID: 0000-0002-1108-716X DOI: https://doi.org/10.14741/ijcet/v.8.4.24 consumer. Therefore it is mostly considered to be a finishing process rather than a preparatory process, which is mainly carried out to facilitate coloration processes (Choudhury, 2017).

Mercerization treatment is carried out using caustic soda which determines the contraction and swelling of the fibres; they become translucent and increase their tensile strength, but reduce their flexural and torsion strength. The bean-like section of the fibre, becomes first elliptic and then circular, allowing a better reflection of light with a consequent increase of luster.

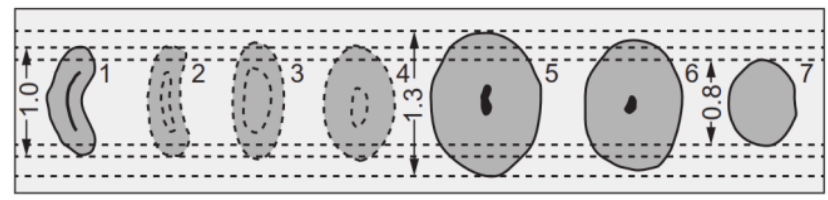

Figure 1: Schematic cross-sectional view of cotton fibre at various stages of mercerization.

Mercerization is usually carried out under tension and the liquor temperature ranges between $15-20{ }^{\circ} \mathrm{C}$ and its uniform absorption is assured by adding mercerizing wetting agents stable in alkaline environment. From a chemical point of view, alkalicellulose is the first material to form; the next material, which forms after repeatedly water washing is hydrocellulose, which is more reactive than natural cellulose. Cotton wetting entails shrinkage of the material, which must be kept under tension, to avoid a fuzzy and woollen appearance (ACIMIT, 2001). 
Mercerization is a well-established finishing process for cotton which affects its fine structure, morphology, mechanical properties and reactivity (Zeronian, 1985). In general, crystallinity and crystallite size are decreased, while the orientation of the cellulose chains with respect to the fibre axis is increased. The native cellulose (i.e. cellulose I crystal lattice) is more or less completely converted to the cellulose II form during mercerization depending on the treatment temperature and the concentration of sodium hydroxide, as well as on the tension applied.

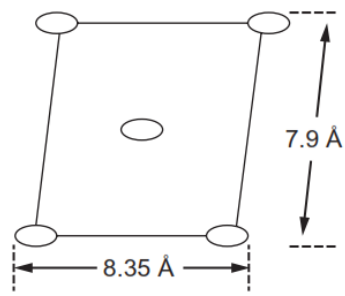

(A)

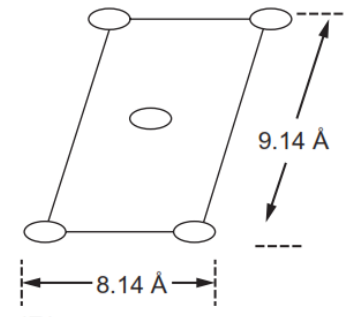

(B)
Figure 2: Schematic lattice structures of (A) cellulose I (native cellulose) and (B) cellulose II.

If tension is applied during the process, the swelling of the cellulose structure is impaired, and the conversion of the crystal lattice to cellulose II is incomplete (Buschle-Diller and Zeronian, 1994).

\section{Effects of Mercerization}

Mercerization changes the cotton fibre surface by removing part of the cuticle and decreasing the wax layer (Jordanov, 2010). Due to a high affinity, caustic soda solution penetrates into the crystalline region, in addition to the amorphous region of fibre. The intermolecular forces are weakened and the strength of the material decreases, but it recovers after deswelling and drying. Due to the distortion of the polymer network and the change in the crystalline structure, the mercerisation process is irreversible.

The degree of swelling during mercerization depends on the concentration of caustic soda. At low concentration $\mathrm{NaOH}$ molecules are hydrated by large number of water molecules and the diameter of the hydrated ions is too large to penetrate into the macromolecular structure of cotton. As the concentration of caustic soda increases, the number of water molecules available for the formation of hydrates decreases and thus hydrated ion pairs are formed which are capable of penetrating into the fiber structure of cotton by breaking hydrogen bonds and weak van der Waal forces between cellulose chains resulting in fiber swelling and the corresponding fiber shrinkage.

Swelling and shrinkage are more when there is no tension in the fiber (Warwicker, 1966). It is also well known that mercerization decreases the amount of crystalline part or increases the amorphous content of the fiber. This increase in the proportion of amorphous part and increased availability of hydroxyl groups $(-\mathrm{OH})$ is directly related to the increase moisture sorption, reactivity and dye absorption of mercerized cotton (Marsh, 1951). The main focus of the present paper is limited to find the effect of caustic soda concentration on physical properties of fibre during mercerization as well as suitable temperature of subsequent dyeing for increased dye uptake.

\section{Reactive Dye}

Reactive dyes form covalent bond with cotton through neucleophilic substitution or neucleophilic addition mechanism and the dyes are familiar as substitutive and additive dyes respectively. Due to presence of strong dye-fibre interaction, fastness properties are remarkably good except wash fastness which is poor to moderate due to hydrolytic nature of dyes. Predissolved dye is applied on cotton; salt is added for better exhaustion followed by fixation with alkali. Subsequent soaping and washing remove all superficial and hydrolysed dyes (Chokraborty, 2010).

\section{Materials and Methods}

\subsection{Fabric}

The fabric with following specifications was used for the study and was collected from Wet Process Engineering Laboratory of Bangladesh University of Textiles.

Table 1: Fabric Specification

\begin{tabular}{|c|c|}
\hline Fabric Type & Properties \\
\hline $\begin{array}{c}\text { Single Jersey Knit } \\
\text { Fabric }\end{array}$ & Loop length 2.5mm, \\
& Yarn count 28 Ne, \\
CPI-28, WPI-35, GSM 798
\end{tabular}

\subsection{Chemicals and Auxiliaries}

Laboratory grade chemicals and auxiliaries were used for the study.

Table 2: Chemicals and Auxiliaries Used

\begin{tabular}{|c|c|}
\hline Chemicals & Used For \\
\hline Caustic Soda & Mercerization \\
\hline Reactive dye & Dyeing \\
\hline Soda Ash & Fixation of Reactive Dyes \\
\hline Soaping Agent & Washing after dyeing \\
\hline Fixing Agent & Aftertreatment process \\
\hline
\end{tabular}

\subsection{Equipment Required}

All the experiments were carried out in the Wet Process Engineering Laboratory of Bangladesh University of Textiles. The following equipment were used for the study. 
Table 3: Equipment Required

\begin{tabular}{|c|c|}
\hline Equipment & Used For \\
\hline $\begin{array}{c}\text { High Temperature } \\
\text { Dyeing Machine }\end{array}$ & Dyeing \\
\hline Spectrophotometer & $\begin{array}{c}\text { Measurement of Color } \\
\text { Strength }\end{array}$ \\
\hline $\begin{array}{c}\text { TITAN Universal } \\
\text { Strength Tester }\end{array}$ & $\begin{array}{c}\text { Measurement of Tensile } \\
\text { Strength }\end{array}$ \\
\hline Crock meter & $\begin{array}{c}\text { Assessment of colorfastness } \\
\text { to rubbing }\end{array}$ \\
\hline Light Fastness Tester & $\begin{array}{c}\text { Assessment of colorfastness } \\
\text { to light }\end{array}$ \\
\hline Gyrowash & $\begin{array}{c}\text { Assessment of colorfastness } \\
\text { to wash }\end{array}$ \\
\hline Grey Scale & Assessment of Color fastness \\
\hline
\end{tabular}

\subsection{Mercerization}

The fabric was immersed at a concentration of caustic of 50, 60 and $70^{\circ}$ Tw respectively at room temperature. The fabric was kept there for 1 minute. It was later neutralized with $1 \%$ acetic acid solution.

\subsection{Dyeing}

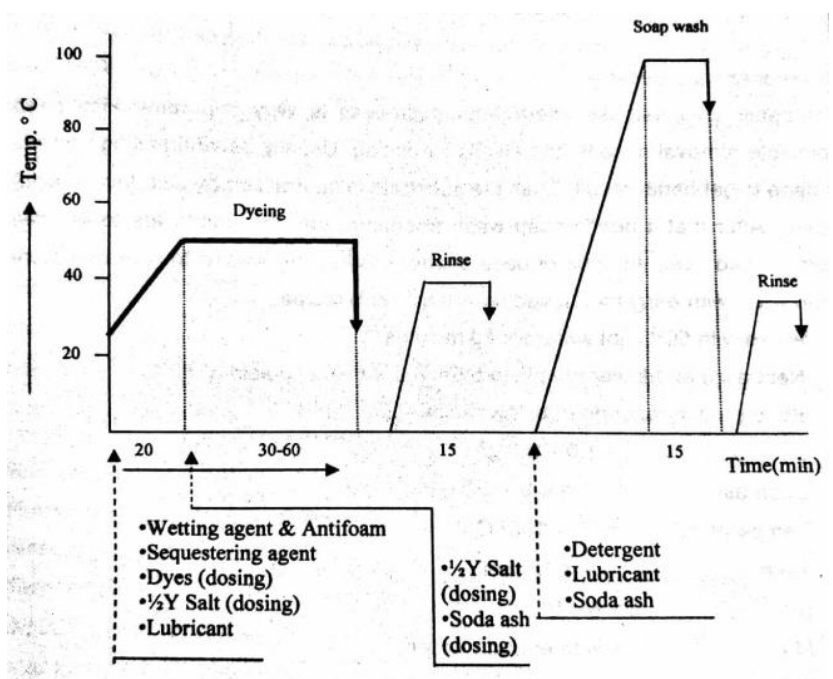

Figure 3: Process Curve of dyeing Cotton Mercerized Knit Fabric with Reactive Dyes.

Table 4: Recipe of Dyeing

\begin{tabular}{|c|c|}
\hline Wetting Agent & $1 \mathrm{~g} / \mathrm{L}$ \\
\hline Sequestering Agent & $1 \mathrm{~g} / \mathrm{L}$ \\
\hline Anti-foaming Agent & $1 \mathrm{~g} / \mathrm{L}$ \\
\hline Reactive Dyes & $3 \%$ o.w.f. \\
\hline Glauber Salt & $50 \mathrm{~g} / \mathrm{L}$ \\
\hline Alkali (Soda Ash) & $12 \mathrm{~g} / \mathrm{L}$ \\
\hline Lubricating Agent & $1 \mathrm{~g} / \mathrm{L}$ \\
\hline Temperature & $20,30,40,50,60^{\circ} \mathrm{C}$ \\
\hline Time & 60 minutes \\
\hline $\mathrm{pH}$ & 11 \\
\hline $\mathrm{M}: \mathrm{L}$ & $1: 8$ \\
\hline
\end{tabular}

The mercerized fabric was dyed with $3 \%$ shade of Reactive dye at temperatures $20^{\circ} \mathrm{C}, 30^{\circ} \mathrm{C}, 40^{\circ} \mathrm{C}, 50^{\circ} \mathrm{C}$ and $60^{\circ} \mathrm{C}$ respectively. Following recipe was used for dyeing (Table 4) and the dyeing process was carried as the process curve in Figure 3. After dyeing, the fabric were neutralized, washed and dried.

\subsection{Characterization}

The tests carried out for the characterization of the mercerized and dyed samples are tabulated in Table 5.

Table 5: List of Test Methods

\begin{tabular}{|c|c|}
\hline Test Method & Test Details \\
\hline ASTM D2495 - 07 & $\begin{array}{c}\text { Standard Test Method for } \\
\text { Moisture in Cotton }\end{array}$ \\
\hline ISO 13934 & Tensile Strength \\
\hline AATCC 89 & Barium Activity Number \\
\hline ISO 105 X12: 1989 & Color fastness to Rubbing \\
\hline ISO 105 B02: 2014 & Color fastness to Light \\
\hline ISO 105C04:1989 & Color fastness to Wash \\
\hline
\end{tabular}

\subsubsection{Moisture Regain}

When the moisture present in a textile material is calculated as a percentage on the oven-dry weight the percentage is known as the regain. It is expressed as percentage.

\subsubsection{Brightness}

It is the relative lightness or darkness of a particular color, from black (no brightness) to white (full brightness).

\subsubsection{Measurement of Tensile Strength}

The resistance of a material to breaking under tension is termed as its tensile strength. TITAN universal tester was used to measure the tensile strength,

\subsubsection{Barium Activity Number}

AATCC Test Method 89 is a common test used for quantifying the degree of Mercerization. It is based on the fabric's ability to absorb barium hydroxide. The procedure is carried out on the fabric both before and after Mercerizing and the barium number is calculated as shown below:

$B A N=\frac{\text { Amount absorbed by Mercerized }}{\text { Amount absorbed by Unmercerized }} X 100$

Unmercerized fabric will give a barium number of 100 to 105 . Completely mercerized fabric will give a barium number of 150 . Commercially treated fabrics fall in a range between 115 to 130 . 


\subsubsection{Measurement of Color Strength}

By using this reflectance value into the Kubelka Munk`s equation, color strength $(\mathrm{K} / \mathrm{S})$ values were measured of the dyed sample.

$\frac{K}{S}=\frac{(1-R)^{2}}{2 R}$

Where, $\mathrm{R}=$ reflectance percentage, $\mathrm{K}=\mathrm{absorption}$ coefficient, $\mathrm{S}=$ scattering co-efficient.

The K/S values were measured by spectrophotometer and a comparison of the values for different mercerizing condition and dyeing time was carried out.

\subsubsection{Colorfastness to Wash}

The resistance of color of textiles to fade or bleed against wash is called color fastness to wash. Gyrowash was used to assess the fastness rating.

\subsubsection{Colorfastness to Rubbing}

The resistance of color of textiles to fade or bleed against rubbing is called color fastness to rubbing. Crock meter was used to assess the fastness rating.

\subsubsection{Colorfastness to Light}

The resistance of color of textiles to fade or bleed against light is called color fastness to light. Light fastness tester was used to assess the fastness rating.

\section{Results and Discussion}

\subsection{Moisture Regain}

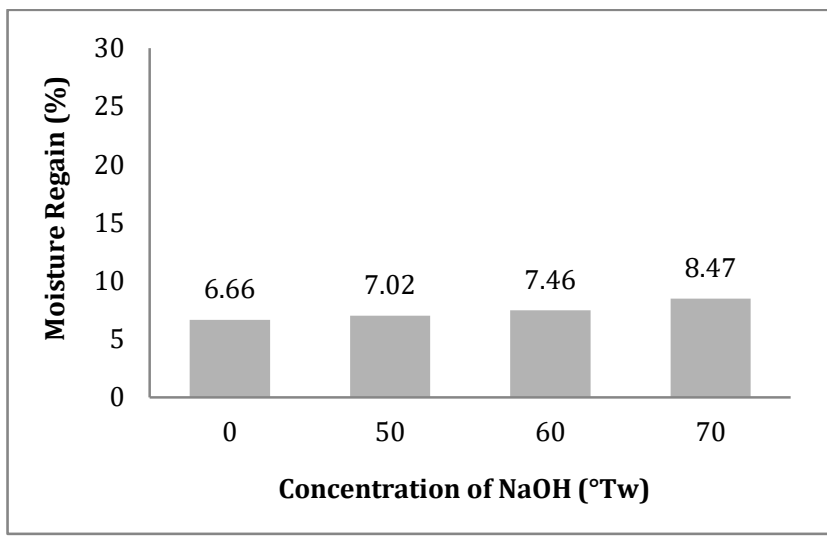

Figure 4: Effect of alkali concentration on moisture regain

From the figure 4, it was found that the value of moisture regain increases with the increase of concentration of $\mathrm{NaOH}$. As the concentration of alkali increases, the amorphousness of the fibre also increases and the canals or spaces within the cellulose structure become more uniform which causes more moisture absorption.

\subsection{Brightness}

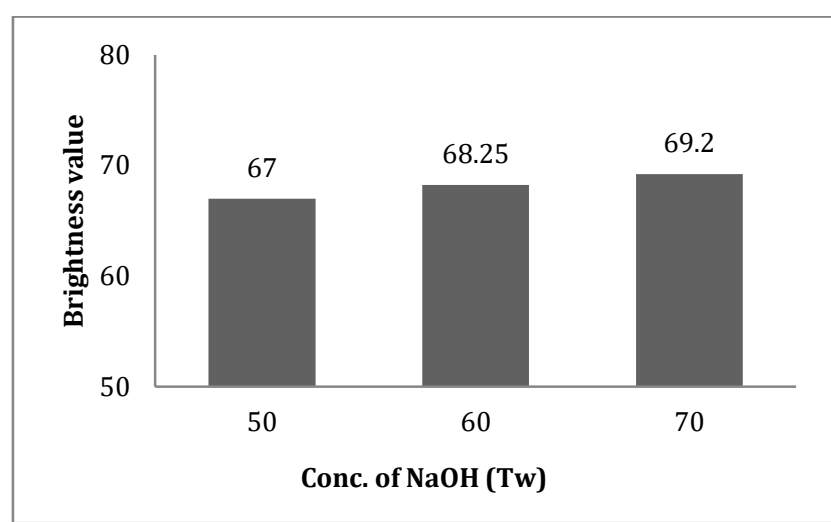

Figure 5: Effect of $\mathrm{NaOH}$ concentration on brightness value

From the figure 5, it was found that, the brightness value increases with the increase of concentration of alkali within same temperature. When the concentration of alkali increases, more swelling takes place in the fibre. As a result the cross section becomes more circular and the surface structure becomes more smooth and regular enabling it to reflect incident light more evenly. So brightness is increased.

\subsection{Tensile Strength}

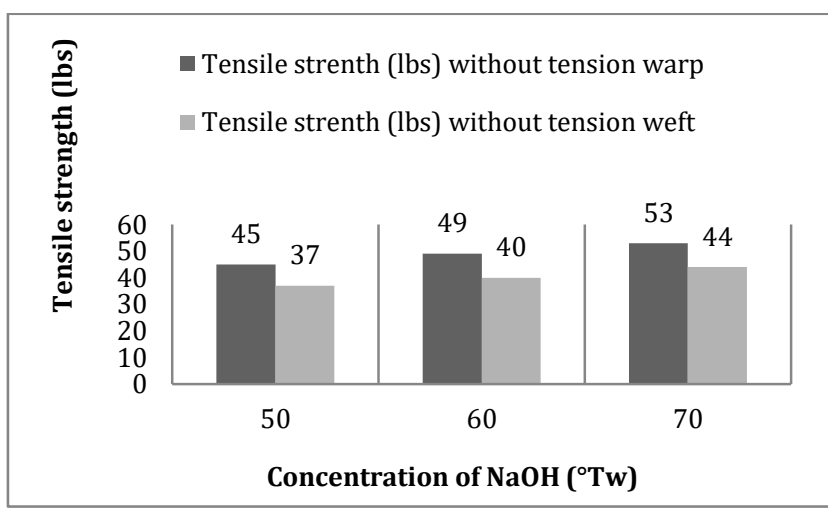

Figure 6: Effect of $\mathrm{NaOH}$ concentration on tensile strength

From the figure 6 , tensile strength was found to increase at both warp and weft direction with the increase of concentration of $\mathrm{NaOH}$ within same temperature $20^{\circ} \mathrm{C}$. As the concentration of alkali increases, more swelling takes place which results molecular alignment in more regular way leading to an increase in hydrogen bond formation. So tensile strength increases with the alkali concentration. 


\subsection{Barium Activity Number}

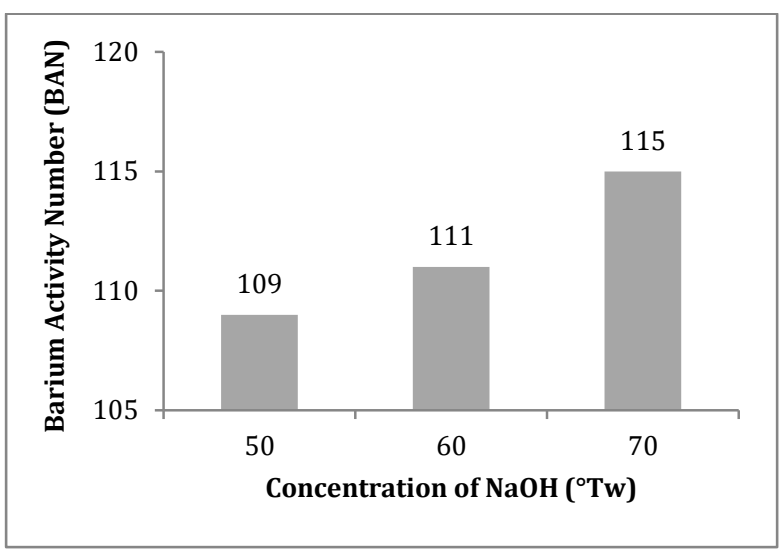

Figure 7: BAN on different $\mathrm{NaOH}$ concentration
From the figure 7, BAN is expressed at various caustic concentrations. Here it was seen that all the values lie above 105 , it can be concluded that mercerization were successful for all the concentration. But for commercially mercerized fabric, BAN is recommended in the range of 115 to 130 . According this, $70^{\circ} \mathrm{Tw}$ concentration of caustic gives the best performance.

\subsection{Measurement of Color Strength}

From the figure 8, Color Strength $(\mathrm{K} / \mathrm{S})$ values of mercerized samples were expressed at various dyeing conditions. It is clearly visible that with the increase of $\mathrm{NaOH}$ concentration, the mercerization performance as well as the corresponding color strength values after dyeing was found successively better.

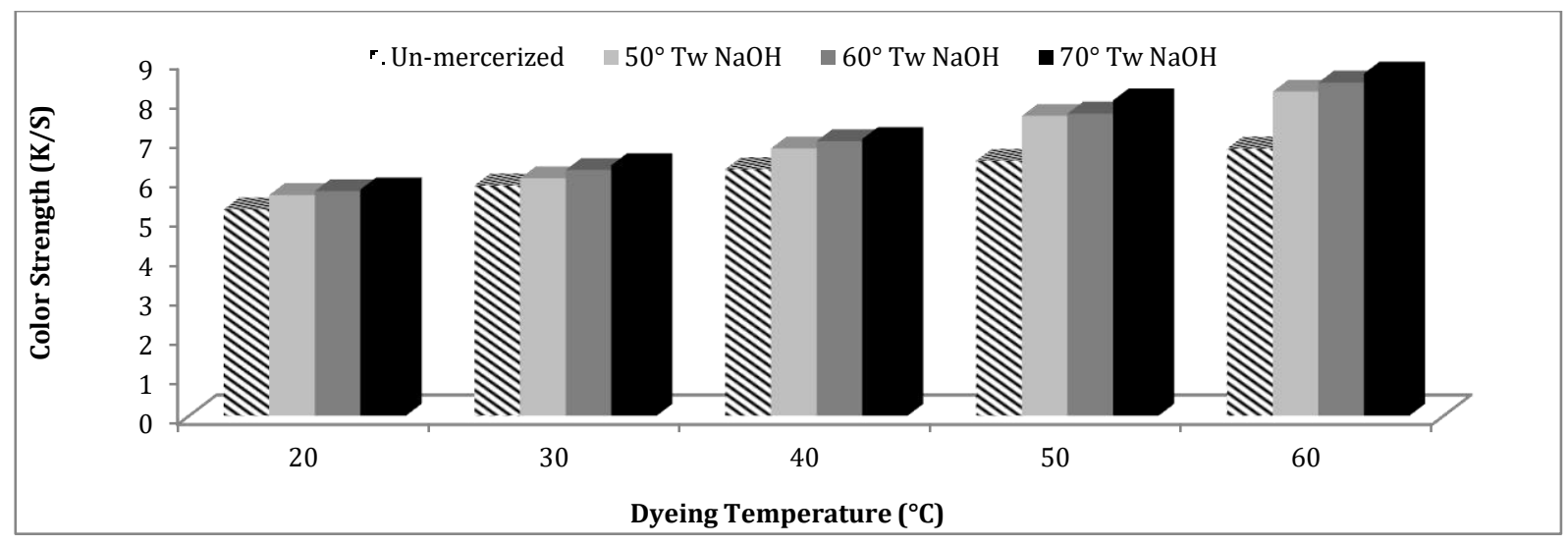

Figure 8: Color Strength $(\mathrm{K} / \mathrm{S})$ values of mercerized samples at various dyeing conditions

Table 6: Color fastness to Wash

\begin{tabular}{|c|c|c|c|c|c|c|c|c|c|}
\hline \multirow{2}{*}{$\begin{array}{c}\text { Caustic } \\
\text { soda conc. } \\
\text { (Tw) }\end{array}$} & \multirow[b]{2}{*}{ Temp. } & \multicolumn{2}{|c|}{ Shade Change } & \multicolumn{6}{|c|}{ Degree of Staining } \\
\hline & & $\begin{array}{c}\text { Un-mercerized } \\
\text { Sample }\end{array}$ & $\begin{array}{c}\text { Mercerized } \\
\text { Sample }\end{array}$ & DA & $\mathrm{CO}$ & PA & PET & $\mathrm{AC}$ & VI \\
\hline \multirow{5}{*}{50} & 20 & 3 & 3 & $3-4$ & $3-4$ & $3-4$ & $3-4$ & 4 & 4 \\
\hline & 30 & $3-4$ & $3-4$ & 4 & $3-4$ & $3-4$ & $3-4$ & 4 & 4 \\
\hline & 40 & $3-4$ & $3-4$ & 3 & 4 & 4 & $3-4$ & 4 & 4 \\
\hline & 50 & $3-4$ & 4 & $3-4$ & 4 & 4 & $3-4$ & 4 & 4 \\
\hline & 60 & $4-5$ & $4-5$ & $3-4$ & 4 & 4 & 4 & 4 & 4 \\
\hline \multirow{5}{*}{60} & 20 & 3 & $3-4$ & $3-4$ & 4 & $3-4$ & 4 & $3-4$ & $3-4$ \\
\hline & 30 & $3-4$ & 3 & $3-4$ & $3-4$ & 4 & 4 & $3-4$ & $3-4$ \\
\hline & 40 & $3-4$ & $3-4$ & 4 & $3-4$ & $3-4$ & 4 & $3-4$ & 3 \\
\hline & 50 & $3-4$ & $4-5$ & 4 & $3-4$ & $3-4$ & 4 & $3-4$ & 3 \\
\hline & 60 & $4-5$ & $4-5$ & 4 & $3-4$ & 3-4 & 4 & 3-4 & 4 \\
\hline \multirow{5}{*}{70} & 20 & 3 & $3-4$ & 4 & $3-4$ & 3 & $3-4$ & $3-4$ & $3-4$ \\
\hline & 30 & $3-4$ & 3 & 3-4 & 3-4 & 3-4 & 3-4 & 3-4 & $3-4$ \\
\hline & 40 & $3-4$ & $3-4$ & $3-4$ & 3-4 & 3-4 & 3-4 & 3-4 & 3 \\
\hline & 50 & $3-4$ & $4-5$ & $3-4$ & 3-4 & 3 & $3-4$ & 3-4 & $3-4$ \\
\hline & 60 & $4-5$ & 5 & $3-4$ & $3-4$ & $3-4$ & $3-4$ & 4 & 3 \\
\hline
\end{tabular}

[DA=Diacetate, $\mathrm{CO}=$ Cotton, $\mathrm{PA}=$ Polyamide, $\mathrm{PET}=$ Polyester $, \mathrm{AC}=\mathrm{Acrylic}, \mathrm{VI}=\mathrm{Viscose}]$

It is well known that, for a desired shade, not only a single parameter is important; rather it is a combination of proper adjustment of all the processing parameters. Accordingly, it was seen that concentration of $\mathrm{NaOH}$ did not affect the color strength values significantly. It was also found that, at fixed 
dyeing time of 60 minutes, best color strength was obtained at maximum dyeing temperature of $60^{\circ} \mathrm{C}$.

\subsection{Color fastness to Wash}

The data is obtained after dyeing the mercerized and un- mercerized fabrics with 3\% reactive dye at an M: L ratio of 1:10. Fastness ratings to wash are tabulated in the Table 6. It is found that, shade change is independent of the caustic conc. but dependent on the dyeing time. Inadequate time creates less fixed tone on the fabric, which causes easy removal during washing. For this at less dyeing time, the shade change rating is poor while at higher dyeing time, it obtained higher grade. While comparing the mercerized and unmercized sample, unmercerized samples were almost similar or a grade less in rating than mercerized ones. In case of staining ratings, several fibres showed several results.

\subsection{Color fastness to Rubbing}

The data is obtained after dyeing the mercerized and un- mercerized fabrics with 3\% reactive dye at an M: L ratio of 1:10. Staining ratings are tabulated in the Table 7. It is found that, staining rating is independent of the caustic conc. but dependent on the dyeing time. With the increasing time of dyeing, the staining rating increases. Actually dyeing is a distribution process of dye molecules in the interior of the fibre. For uniform shade depth, optimum dyeing time is necessary and inadequate time creates less fixed tone on the fabric, which causes easy removal at the rubbing test.

Table 7: Color fastness to Rubbing

\begin{tabular}{|c|c|c|c|c|}
\hline \multirow{2}{*}{$\begin{array}{c}\text { Dyeing } \\
\text { Temp. } \\
\left({ }^{\circ} \mathrm{C}\right)\end{array}$} & $\begin{array}{c}\text { Un-mercerized } \\
\text { Sample }\end{array}$ & \multicolumn{4}{|c|}{$\begin{array}{c}\text { Mercerized Sample } \\
\text { Caustic soda conc. }\left({ }^{\circ} \mathrm{Tw}\right)\end{array}$} \\
\cline { 2 - 5 } & 2 & 50 & 60 & 70 \\
\hline 20 & $2-3$ & $2-3$ & $3-4$ & $3-4$ \\
\hline 30 & 3 & $2-3$ & $3-4$ & $3-4$ \\
\hline 40 & 3 & 3 & 4 & $3-4$ \\
\hline 50 & $3-4$ & $3-4$ & 4 & $3-4$ \\
\hline 60 & & & & \\
\hline
\end{tabular}

\subsection{Color fastness to Light}

The data is obtained after dyeing the mercerized and un- mercerized fabrics with 3\% reactive dye at an M: L ratio of $1: 10$. Fastness ratings to light are tabulated in the Table 8. It is found that, shade change is independent of the caustic conc. but dependent on the dyeing time. Inadequate time creates less fixed tone on the fabric, which causes easy removal at the light fastness test.
Table 8: Color fastness to Light

\begin{tabular}{|c|c|c|c|c|}
\hline \multirow{3}{*}{$\begin{array}{c}\text { Dyeing } \\
\text { Temp. }\left({ }^{\circ} \mathrm{C}\right)\end{array}$} & \multicolumn{4}{|c|}{ Shade Change } \\
\hline & \multirow{2}{*}{$\begin{array}{c}\text { Un- } \\
\text { mercerized } \\
\text { Sample }\end{array}$} & \multicolumn{3}{|c|}{$\begin{array}{c}\text { Mercerized Sample } \\
\text { Caustic soda conc. }\left({ }^{\circ} \mathrm{Tw}\right)\end{array}$} \\
\hline & & 50 & 60 & 70 \\
\hline 20 & 2 & $2-3$ & $2-3$ & 3 \\
\hline 30 & $2-3$ & 3 & $3-4$ & 3 \\
\hline 40 & 3 & $3-4$ & $3-4$ & $3-4$ \\
\hline 50 & 3 & 4 & $4-5$ & 5 \\
\hline 60 & $3-4$ & $4-5$ & 5 & 5 \\
\hline
\end{tabular}

\section{Conclusion}

Mercerization is a chemical treatment of improving multifunctional properties of cellulosic fibres. In this study, mercerizing efficiency and the effect of mercerizing condition on physical properties is assessed in terms of moisture regain, tensile strength and brightness of cotton goods. It was found that the value of moisture regain increases with the increase of concentration of $\mathrm{NaOH}$. Tensile strength and brightness values also increase with the alkali concentration. The mercerized fabric, when dyed with reactive dyes, showed better color strength and fastness properties. In terms of colorfastness properties, it was observed that, shade change and staining values are slightly dependent on the concentration of alkali. Rather, with the increment of dyeing time the color becomes more stable with better fastness rating. Lesser dyeing time results in poor fastness rating in all the rubbing, light and wash fastness tests.

\section{Acknowledgement}

The authors are thankful to Emran Hossain, Lecturer, Department of Wet Process Engineering, Bangladesh University of Textiles for his contribution to data preparation and presentation.

\section{References}

A. K. Roy Choudhury (2017), "Acid-alkali finish" in Principles of Textile Finishing, Chapter 5, Page 79, 82, Woodhead Publishing.

P. Bellini et al (2001), Finishing Italian Book, Page 12, ACIMIT Foundation.

S.H. Zeronian et al (1985), "Cellulose Chemistry and Its Applications", Page 159, John Wiley and Sons, New York.

G. Buschle-Diller et al (1994), "Enzymatic and acid hydrolysis of cotton cellulose after slack and tension mercerization", 26 (4) Page 17-24, Text. Chem. Color.

J. Jordanov et al (2010), "Changes in the non-cellulosic components of cotton surface after mercerization and scouring". 10 (6), Page 65-72, AATCC Rev.

J.O. Warwicker (1966), "A Review of the Literature on the Effect of Caustic Soda and Other Swelling Agents on the Fine Structure of Cotton - Cotton, Silk and Man-Made Fibers Research Association"; Manchester, UK.

J.T. Marsh (1951), "Mercerizing", Chapman and Hall, London. 